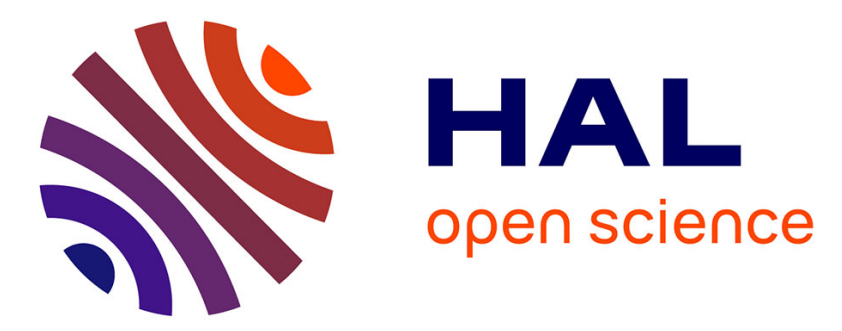

\title{
A Methodology for Improving Enterprise Performance by Analysing Worker Capabilities via Simulation
}

\author{
Brian Patrick Kernan, Andrew Lynch, Con Sheahan
}

\section{To cite this version:}

Brian Patrick Kernan, Andrew Lynch, Con Sheahan. A Methodology for Improving Enterprise Performance by Analysing Worker Capabilities via Simulation. International Journal of Production Research, 2011, pp.1. 10.1080/00207543.2010.527387 . hal-00660537

\section{HAL Id: hal-00660537 https://hal.science/hal-00660537}

Submitted on 17 Jan 2012

HAL is a multi-disciplinary open access archive for the deposit and dissemination of scientific research documents, whether they are published or not. The documents may come from teaching and research institutions in France or abroad, or from public or private research centers.
L'archive ouverte pluridisciplinaire HAL, est destinée au dépôt et à la diffusion de documents scientifiques de niveau recherche, publiés ou non, émanant des établissements d'enseignement et de recherche français ou étrangers, des laboratoires publics ou privés. 


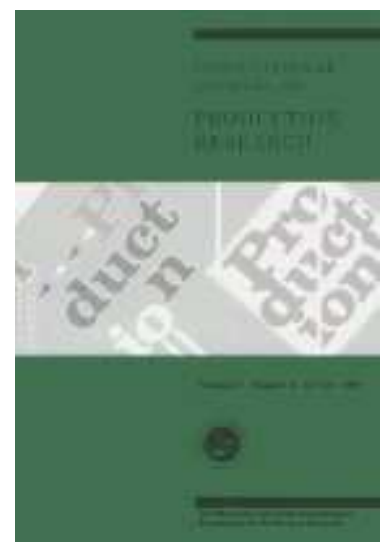

\section{A Methodology for Improving Enterprise Performance by Analysing Worker Capabilities via Simulation}

\begin{tabular}{|r|l|}
\hline Journal: & International Journal of Production Research \\
\hline Manuscript ID: & TPRS-2010-IJPR-0504.R1 \\
\hline Manuscript Type: & Original Manuscript \\
\hline $\begin{array}{r}\text { Date Submitted by the } \\
\text { Author: }\end{array}$ & 19-Aug-2010 \\
\hline Complete List of Authors: & $\begin{array}{l}\text { Kernan, Brian; University Limerick, Enterprise Research Centre } \\
\text { Lynch, Andrew; University of Limerick, Enterprise Research Centre } \\
\text { Sheahan, Con; University of Limerick, Enterprise Research Centre }\end{array}$ \\
\hline Keywords: & STOCHASTIC MODELS, SIMULATION APPLICATIONS \\
\hline Keywords (user): & \\
\hline
\end{tabular}

\section{SCHOLARONE Manuscripts}




\title{
A Methodology for Improving Enterprise Performance by Analysing Worker Capabilities via Simulation
}

\author{
Brian Kernan, Andrew Lynch, Con Sheahan
}

Manufacturing Operations \& Engineering, University of Limerick, Limerick, Ireland

\author{
Brian Kernan, Engineering Research Building, University of Limerick \\ Andrew Lynch, Engineering Research Building, University of Limerick \\ Dr. Con Sheahan, Engineering Research Building, University of Limerick
}

In this paper we outline a methodology for improving the overall performance of small to medium sized enterprises (SMEs) by analysing worker capabilities through simulation and modelling. We firstly examine key performance indicators (KPIs) of the SME in its as-is state. The primary KPIs we examine are the resource constraint metrics (RCMs) and customer misery index (CMI). The RCMs help to identify the skill that is the biggest contributor to the overall system constrainedness. The CMI is a measure of customer demand satisfaction. By increasing the supply of the most heavily constrained skill we should increase the flow of work orders through the system, which will in turn result in a reduced CMI, or at least provide a potential for more work orders to flow through the system. We run a set of experiments on data from a real factory, which upgrades the skill sets of workers with the most heavily constrained skill, and then we look at the system improvement. The overall impact of this experimental methodology is that it can make recommendations to an organisation about which worker to upgrade with which skill, and how the training should be implemented, to yield the optimal improvement to the enterprise.

Keywords: Worker, Skill, Training, SMEs, Resource Constraint Metric, Customer Misery Index 


\section{Introduction}

Managing directors of SMEs (Small to Medium Sized Enterprises) consistently find personnel capability a limiting factor in influencing key performance measures. Consequently worker training is viewed as an important tactical decision scenario for an organisation. Previous research has shown that the implementation of training programs in companies can yield substantial productivity gains (Bartel 1994), and is important for a company's growth and its ability to stay competitive (Mital et al. 1999). As part of our research we carried out a survey on $40 \mathrm{SME}$ owner-managers on whether or not a computer aid such as simulation would be a useful tool for making a decision on worker training. The results are shown in Figure 1. Over 80\% of participants either agreed or strongly agreed that a computer tool that could rank candidate workers based on the improvements they could bring to the enterprise would be useful in making a decision on worker training. $<$ FIGURE 1. HERE >

Discrete event simulation (DES) lends itself well to the training decision scenario. We use DES as a prediction tool to determine which worker we should upgrade that will yield the best improvement to the enterprise. DES is preferable over other simpler, deterministic models, since it can deal with stochastic variables such as machine processing times, purchase order fulfilment lead-times, and worker absenteeism; it can thus quantify the risk of certain events on the enterprise's performance.

Traditional simulation models however, do not generally look at the effect of personnel capability. In fact simulation models tend to focus on heavily automated production lines where the human element can be disregarded. For the majority of SMEs however, workers are a critical resource and cannot be ignored in a simulation model. A simple decision scenario that is dealt with in conventional DES models is looking at the effect of adding an extra parallel machine to a production line has on the system throughput. The training decision scenario expands on this by dealing with workers as a resource and looking at improving their skill-sets. A worker's skill can be seen as an abstract resource that is requested by a machine in its different modes of operation. For example, a machine in its setup mode of operation may request the skill 'Can Setup Machine' which would be provided by an operator. The same machine, in a maintenance mode of operation may request a different skill such as 'Can Repair Machine' that is provided by a technician. 
The main precedent for our research is in the paper "Simulation of Group Work Processes in Manufacturing" by Bernhard et al. (Bernhard et al. 1997). In this paper an assembly operation with 15 different assembly stations is looked at where workers are either fully or partially qualified. The authors then examine two situations; one where all workers are fully qualified for every process, and then where a minimal set of workers are partially upgraded that yields optimal improvements that are comparable to the first situation. In our paper we refer to the situation where all workers are fully qualified for every process as the Magic Wand Scenario.

It should be noted that in the paper by Bernhard et al. the only output considered is throughput. For our research we developed holistic KPIs that speak to the entire organisation. These KPIs are covered in Section 4. We also expand upon the work by Bernhard et al. by having a methodology for worker training that is applicable to the general enterprise. 


\section{Modelling Workers in Simulation}

We have built a database driven general simulation model that instantiates an enterprise from information stored in a relational database. The main entities that we store are information on machines (with multiple modes of operation), workers, suppliers (vendors/subcontractors), workflows, activities, resource calendars, and orders. Workers can be assigned multiple skills, and for each worker-skill combination we have the following information:

- Efficiency - A value between $1 \%$ and $100 \%$ and affects processing speed. For example if the nominal processing time for a job is 5 minutes, and if the worker assigned to the job has an efficiency of $50 \%$ for the requested skill, then the actual processing time will be 10 minutes (we simply divide the nominal processing time by the efficiency).

- Conformance Rate - A value between $0 \%$ and 100\%. Conformance rates will be connected to worker dependent quality issues for machines. For example, if a machine has a quality issue, and the worker's conformance rate for the requested skill is $96 \%$, then $4 \%$ of the workpieces will have a quality issue and will either be scrapped or reworked. Quality related needs have been identified as being an important impetus for training (Swamidass 2003).

- Grade - A single character that is either 'A', 'B', 'C', or 'D'. Skill grades will be connected with a machine for a particular activity, which also possess the attribute grade. For example, a difficult machine-activity for a job could have a 'B' grade indicting that only a worker with a grade ' $\mathrm{B}$ ' or higher for the requested skill can be utilised for the job. Grades in practice will be dependent on efficiency and/or conformance rate, but can be defined independently in the database i.e. a worker with an 'A' grade for a skill should have a higher efficiency and/or conformance rate for a worker with a 'B' grade for the same skill.

For the sake of simplicity, in the case-study in Section 6 we assume that all efficiencies are either $0 \%$ or $100 \%$ i.e. a worker either possesses a certain skill or he does not. Also we do not deal with non-conformance issues and grades; these are defaulted to values of $100 \%$ and 'A' respectively. It is also important to note that the simulation model is pull-based. Orders are generated externally by an ERP (Enterprise Requirements Planning) system based on external customer demand and product BOMs (Bill of Materials). All orders in the system 
1

2

4

5

6

7

8

9

10

11

12

13

14

15

16

17

18

19

20

21

22

23

24

25

26

27

28

29

30

31

32

33

34

35

36

37

38

39

40

41

42

43

44

45

46

47

48

49

50

51

52

53

54

55

56

57

58

59

60

are tied to external demand. This means that the simulator is more representative of reality than the paper (Bernhard et al. 1997) which only looks at increased throughput - an increase in throughput is only beneficial if there is actual demand for the additional product being produced. 


\section{Training Periods}

Overall, training leads to acquiring new skills and/or improvements in existing skills (Carnevale et al. 1990) and we simulate training as such. Actual training periods are assumed to have granularity of days, and we associate a set of upgrades with each trainee for a training period. Training itself can be undertaken in two different ways:

- Hands-Off Training - We assume that the trainee is unavailable for work. This will be applicable if the worker is receiving off-the-job training i.e. on the shop-floor but unavailable for work e.g. observing another worker operating a machine. Once the training period is complete, the trainee receives their upgrades.

- Hands-On Training - The trainee is available for work on the shop-floor. This is also known as on-the-job training (OJT) (Rothwell et al. 2004). A survey by the National Association of Manufacturers in the US revealed that OJT was the leading training method, with over $77 \%$ of manufacturers using it for developing employees (Swamidass 2003). We assume in our model that trainees are given their upgrades at the start of hands-on training.

Since we can associate multiple training periods with a worker, we can create a string of training periods. For example, over the course of a working week the trainee could receive hands-off training Monday through Wednesday and on Thursday and Friday the trainee is given hands-on training. As the week progresses the trainee's performance rate can improve. For the sake of simplicity we assume all training is carried out by the enterprise under examination i.e. training is not sub-contracted out, and thus there are no associated monetary costs. 


\section{Training KPIs}

We will have four KPIs or benchmarks that we will base our decision for training on:

1. System Constraint Metric (SCM) - This is a measure of the total constrainedness of the manufacturing system. The lower it is, the faster the order velocity through the system. The SCM is the sum of Resource Constraint Metrics (RCMs) which individually are a measure of how much of a limiting factor a resource is. RCMs are defined in our previous paper (Kernan et al. 2010).

2. Customer Misery Index (CMI) - The customer misery index is a metric which weights the lateness of a satisfied sales order by its contributing revenue. The equations for $\mathrm{CMI}$ are given below. The $\mathrm{CMI}$ is a measure of revenue at risk. If the enterprise is chronically late in satisfying demands, after training is implemented, we may see a reduction in the CMI.

$C M I=\sum_{i=1}^{b}\left[\right.$ Revenue $_{i} *$ Lateness $\left._{i}\right]$

【Lateness $\rrbracket_{1} i=\left\{\left(\left(C\right.\right.\right.$ Completion Date $\rrbracket_{1} i-\llbracket$ Request Date $\left.{ }_{1} i\right) /\left(\right.$ [Request Date】 ${ }_{1} i-\llbracket$ Booh

CMI = Customer Misery Index

Revenue $_{i} \quad=\quad$ Revenue Generated from Sales Order Line $i$

Lateness $_{i} \quad=\quad$ Lateness for Sales Order Line ${ }^{i}$

Completion Date $_{i}=$ Completion Date of Sales Order Line $^{i}$

Request Date $_{i} \quad=\quad$ Customer Request Date for Sales Order Line $i$

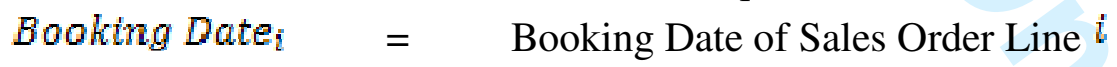

$b \quad=\quad$ Total number of Sales Order Lines

Note in the above equation for lateness, if the request date is before or the same as the booking date, the denominator will be for a single day and in the same units as the numerator e.g. 1 Day, 24 Hours, 1440 Minutes.

3. Cognitive Assessment Metrics - These are an amalgamated set of answers to qualitative yes/no questions with regard to each candidate worker. Pre-set parameters are outlined for each matrix, which facilitates a yes/no answer for each. The purpose here is to allow a qualitative filter to be applied to the various candidates 
for training programs, based on their overall suitability and stability for the company going forward. There are ten questions in total, so each worker will have a rating between 0 and 10. These metrics were determined through surveys and interviews with several owner managers of SMEs and are listed below:

1. Discipline Issues (above/below $\mathrm{x}$ formal issues)

2. Length of Service (above/below x number of years)

3. Location on Shop-Floor (in relevant location or not)

4. Absenteeism (above/below $\mathrm{x}$ incidents per annum)

5. Tardiness (above/below $\mathrm{x}$ incidents per annum)

6. Training received to date (above/below x process operations)

7. Age (inside/outside age bracket)

8. Union Activity (above/below x level of activity)

9. Marriage $(\mathrm{Y} / \mathrm{N})$

10. Mortgage $(\mathrm{Y} / \mathrm{N})$

4. Training Customer Misery Index - When the worker is being trained, they may be unavailable for work. Therefore, there may be a significant increase in the CMI that must be taken into consideration. Staggered training might be required in order to reduce the $\mathrm{CMI}$ that is a result of the training.

\subsection{Standardised RCM across Shifts}

Since an enterprise can have more than shift, it may be found that a skill has a higher RCM value during one shift than another. For example, there may be fewer workers available for the night-shift than the day-shift, and this would mean a higher RCM value for the skill during the night shift. A consequence of this is that if we are looking at potential candidates for trainee we should focus on workers that work the night shift, as opposed to the day shift. To quantify this potential variation in RCM values amongst shifts we need to filter the values by shift. We also need to standardise the RCM value for a particular skill for a particular shift. This is down by dividing the RCM value by the number of workers who possess that skill during that shift.

$$
R C M_{i j}^{8}=\frac{R C M_{i j}}{w_{i j}}
$$

$R C M_{i j}^{*} \quad=\quad$ Standardised RCM for Skill $i$ and Shift $j$ 
$R C M_{i j} \quad=\quad$ RCM for Skill $i$ and Shift $j$

$w_{i j} \quad=\quad$ Total Number of Workers that Possess Skill $i$ during Shift $j$

The reason we divide by the number of workers who currently possess that skill is explained in the following example. Consider the situation for a single shift with a skill 'Can Operate Lathe' with a high RCM say an arbitrary value of 100 hours. If there are currently 10 workers who possess this skill, upgrading a single worker will only increase our skill capacity from 10 to 11 i.e. a $10 \%$ increase. If we have a skill 'Can Weld' with a lower RCM of 90 hours but if there are only 2 workers who possess this skill, then upgrading a skill worker with this ability will increase the skill capacity for welding by $50 \%$. Hence we can say the skill 'Can Operate Lathe' has a standardised RCM value of 10 Hours, and the skill 'Can Weld' has a standardised RCM value of 45 hours. In a sense, this means we focus on not the most highly constrained skill, but the skill that will give us the greatest reduction in constrainedness, with minimum worker capability upgrades. 


\section{Experimental Methodology}

The experimental methodology is defined below. The Magic Wand Scenario is when we instantly upgrade all workers with all skills.

1. Run the baseline experiment for a fixed amount of simulated time (e.g. 6 months)

2. Run the Magic Wand Scenario for the same amount of simulated time

3. Compare the KPIs; if there is a significant improvement go to point 4

4. Identify the most heavily constrained skill and what shift it occurs in; it will have the highest $R C M_{i j}^{*}$ value from the baseline experiment. Also, some qualitative ranking of the problem skill may be required at this stage. For example, it is easier to trainer a worker in a pick-and-place style operation as opposed to a more labour intensive skill such as welding.

5. Determine the following attributes for all workers:

- Does the worker already possess the problem skill? If they do, they are not a candidate for training.

- Does the worker work the shift were the problem skill is most heavily constrained? If they do, they are a candidate for training.

- Cognitive Assessment Metrics - Qualitative metrics for candidates between 0 and 10 (inclusive); the higher the better.

- Total Utilisation - It is reasonable to assume that a worker with low utilisation is a better candidate for training than one with high utilisation. However, even if the candidate worker has high utilisation and if we train them, the simulated worker-pool could reorganise itself to take advantage of this additional skill, and yield high improvements in the KPIs.

6. Filter out workers that already possess the problem skill. Sort remaining workers by descending cognitive assessment metrics, and by ascending utilisation. At this stage we can apply filters to the workers i.e. specify cut-off points for cognitive assessment metrics, and/or utilisation. This implies however, that we do not consider any potential simulated improvements these workers can bring to the KPIs if they were trained.

7. Run experiments, each experiment will be in two parts:

- Run one experiment where candidate(s) is upgraded instantaneously (Part a)

i. Record SCM for all Replications

ii. Record CMI for all Replications 
- Run other experiments where the same candidate(s) receives training (Part b)

i. Record CMI for all Replications

8. Store the information in the table with the following fields ${ }^{1}$ :

- Decision (Primary Key) - Includes Baseline which represents a null decision

- Mean SCM Reduction WRT Baseline - From Experiment (Part a) representing long term steady state improvement

- Mean CMI Reduction WRT Baseline - From Experiment (Part a) representing long term steady state improvement

- Cognitive Assessment Metric - Not Applicable in Baseline Decision

- Mean Training CMI - CMI from Experiment (Part B) minus CMI from Experiment (Part A)

9. Make a pareto-optimal decision based on this table. The ideal (non-dominated) candidate to receive training would possess the following properties:

- Field Mean SCM Reduction WRT Baseline is the highest

- Field Mean CMI Reduction WRT Baseline is the highest

- Field Cognitive Assessment Metric is the highest

- Field Mean Training CMI is the lowest

\subsection{Additional Considerations}

We need to simulate a reasonable long period of time, since the decision on training is a tactical one i.e. we are interested in long-term steady state improvements to the enterprise. A reasonable simulated time would be six months to a year. It is important to note that the mean SCM \& CMI reduction are representative of the long-term benefits from training; they ignore any transient detrimental effects incurred during the training period(s), which are instead captured in the mean training CMI metric.

A reduction in mean CMI indicates real improvement to the enterprise; less customer demands are being satisfied late. A reduction in mean SCM represents a potential for increased resource loading. We could ramp up production if we have more capacity, which will be evidenced by the lower SCM value, but production should only be increased if we can create more demand which may be constrained by market conditions. However we do not

\footnotetext{
${ }^{1}$ Mean Reductions will only be non-zero if there are statistically significant reductions WRT to the baseline model at a significance level of $1 \%$.
} 
consider increasing demand in the experimental methodology, and we may also have no change in the CMI if we are already meeting our customer demands on time.

Also, training two workers concurrently may lead to better improvements in the long term than just training a single worker, but it could lead to a high CMI during the training period, since we have decreased resource capacity while both workers are being trained. If we are still keen on training two workers, we could try staggered-training. We largely ignore this level of detail in the experimental methodology, but the end-user can define these as experimental parameters in the simulation model. 


\section{Case Study}

In this section we go through a simulation experiment using data from a real factory to determine the optimal worker to train. The factory under examination is a SchuF Fetterolf production plant in Ireland that designs and manufactures industrial valves that control, isolate, divert, or sample gases, liquids, slurries, or powders. The model instance data was stored in the company's ERP system and was translated and stored in the Relational Database for the simulation model. The main characteristics of the plant are listed in our previous paper (Kernan et al. 2010) which the reader is referred to. <TABLE 1. HERE>

The worker-skill matrix is shown in Table 1 . We model worker absenteeism and tardiness as described in (Kernan et al. 2010) and we run the model for a simulated period of one year for 20 replications. The top three highest Skill RCM values are shown in Figure 2. One can see that there is significant variance, due primarily to worker absenteeism. Note that in this case study, the factory only operates a single shift - so we do not have to worry about RCM values across different shifts. In Table 1. the skills in the darker cells are the skills with the top three highest Skill RCM values. Worker 1 is the worker with the lowest utilisation and Worker 11 has the highest utilisation (See Figure 3.). We will run worker capability experiments on these two workers with all skills. $<$ FIGURE 2. HERE $><$ FIGURE 3. HERE $>$

It appears that the skill with the highest RCM value is 'Can Welding', however we need to standardise the Skill RCM values by dividing by the number of workers that possess each skill as described in Section 4.2. In Figure 2. we see that the skill with the highest mean standardised RCM value is 'Can Weld'. An important point here is that it may be easier to train a worker in an assembly role, compared with a more skill focused job such as welding.

Next we look at the worker utilisation which is shown in Figure 3. Firstly it should be noted that the low worker utilisation is primarily due to only a limited number $(21 \%)$ of manufacturing workflows being assigned to work orders in the ERP database; instead just a lead-time is specified. In addition it is believed that some of the resource groups in the ERP database have been incompletely filled by the user; most machines are defined to run automatically, even in their setup mode i.e. they require no worker to setup the machine. Finally, in the ERP database there were 24 workers listed, but in Figure 3. it seems that only 11 workers are working on the shop-floor. There reason for this discrepancy is that not all the workers are assigned to the shop-floor e.g. some workers are assigned to sales, accounting etc. However, even though the utilisations are low, we can still measure significant 
differences amongst workers, and amongst experiments. In a sense the Schuff data we are using can be regarded as a data subset of the real world data.

Based on the worker utilisation values it appears that Worker 11 is the most appropriate candidate since he has the lowest utilisation, also he has two skills which have relatively low Skill RCM values. The actual reason this particular worker has such relatively low utilisation is because he is the manager of the plant and thus spends relatively little time on the shopfloor. In reality his role would preclude him from being a training candidate, but for the sake of interest, he was considered a candidate for this simulation experiment.

We next run 10 more experiments, the details of which are shown in the first two columns of Table 2. Note that experiment number 0 corresponds to the baseline. We look at the upskilling of Worker 11 and Worker 1, (the workers with the lowest and highest utilisation respectively) with each skill that they do not currently possess. According to the methodology we should find the best result with Worker 11 and the skill 'Can Welding', since Worker 11 has the lowest utilisation and the skill 'Can Welding' has the highest standardised RCM value. All experiments have been run for 20 replications. <TABLE 2. HERE $>$

Experimental results are shown in Table 2. ANOVA was performed on the experimental results using an ODBC connection to ' $\mathrm{R}$ ' the statistics application. We show the RCM/SCM improvement of each of the worker capability experiments with respect to the baseline experimental model ${ }^{2}$. Percentages are only shown if there is a statistically significant difference ( $1 \%$ significance level) between the means of the two experiments. Also, all results were checked using a K-S test to see if there was any evidence of deviation from the normal model assumption. All data sets appear to be normally distributed. A discussion of the results obtained is covered in the next sub-section.

\footnotetext{
${ }^{2}$ There are no statistically significant improvements to CMI due to long order lead times, relatively short order fulfilment lead-times, and that only $21 \%$ of orders had workflows that utilised worker resources.
} 


\subsection{Discussion}

There are several points of interest from the results shown in Table 2.:

\section{Magic Wand Scenario leads to a $22 \%$ reduction in SCM}

When we break this result down we see that we have a 99\% reduction in Skill RCM, and a $0 \%$ reduction in Machine RCM. So giving ever worker every skill means that machines are practically never starved for skill. However, this scenario does not bring about a significant change in the Machine RCM. This result was to be expected since we have not made any changes to the machines on the shop-floor.

\section{Only Worker 11 brings about improvements}

Only upgrading Worker 11 brings about improvements, and these are limited to the three skills with the highest $\mathrm{RCM}^{*}$ value. These results were expected because Worker 11 has the lowest utilisation, and skills with low $\mathrm{RCM}^{*}$ values should yield commensurately low improvements; in this case zero improvements. Worker 1 has the highest utilisation and upgrading his skill set brings no improvements to the RCMs. It should be noted that for this experiment we only look at upgrading a worker with a single skill at any one time; we cannot discount the possibility that upgrading Worker 1 with multiple skills can lead to improvements. However, we deliberately limit the decision space, since it would be too large to explore otherwise.

\section{Other Points}

Some final points are firstly that for all the experiments there are no significant changes in the Machine RCM values. These results are expected since no changes to the machine are made. Finally in cases where there are significant improvements, the ratio of improvement of RCM Skill to SCM is approximately four. This ratio is expected to be more or less constant in these cases, since the SCM is simply the sum of Skill RCM and Machine RCM, but it is an important value for showing the contribution of constrainedness due to skills and machines to the overall system. 


\section{Conclusion}

In this paper we have looked at worker capability analysis and worker training as an important tactical decision making scenario. Managing directors of SMEs consistently find personnel capability a limiting factor in influencing KPIs. Through the use of a database driven simulation model we provide a methodology for analysing an enterprise's as-is performance and locating where the enterprise should focus its effort in order to improve overall performance with regard to worker capabilities. We essentially determine that skill which is the largest contributor to the overall shop-floor constrainedness. Once we have identified the problem skill we then outline a methodology for determining the quantitative long-term holistic improvement to the enterprise, that would be brought about by upskilling a worker. We also rank and filter candidate workers according to a set of qualitative criteria, that would be infeasible to model in a simulator e.g. discipline issues, number of years with the company. Finally, we describe how the training itself may be carried out in simulation; either as hands-on or hands-off training.

While we have developed an application for the end-user to determine the cognitive assessment metrics, for potential worker candidates, further work is required to incorporate this into the simulation application, and to also develop a robust user interface for experimentation. For example, the user could be presented with a matrix like in Table 1. and once the first six steps of the training methodology have been executed automatically, recommendations for which worker to train and in which skill could be highlighted in the matrix. The user can then run comparative experiments, following these recommendations (or defining their own experiments if they so wish), and then comparing the SCM and CMI benchmarks to the baseline. Once they have established which worker they want to upgrade, experiments could be run on how best to carry out the training. 


\section{References}

Bartel A.P. (1994) "Productivity Gains from the Implementation of Employee Training Programs“" Industrial Relations Vol. 33: pp. 411-425

Bernhard W., Schilling A. (1997) "Simulation of Group Work Processes in Manufacturing" Winter Simulation, Renaissance Waverly Hotel, Atlanta, Georgia, USA, December 7-10, 1997

Carnevale A.P., Goldstein H. (1990) "Schooling and training for work in America: An overview" New developments in worker training: A legacy for the 1990s. Industrial Relations Research Association Series (Ferman L., et al., Eds.), Madison, Wisconsin, USA: Industrial Relations Research Association

Kernan B., Lynch A. Tung D., Sheahan C. (2010) "A Novel Metric for Determining the Constraining Effect of Resources in Manufacturing via Simulation" International Journal of Production Research [ACCEPTED, NOT YET PUBLISHED]

Mital A., Pennathur A., Huston R.L., Thompson D., Pittman M., Markle G., Kaber D.B., Crumpton L., Bishu R.R., Rajurkar K.P., Rajan V., Fernandez J.E., McMulkin M., Deivanayagam S., Ray, P.S., Sule D. (1999) "The Need for Worker Training in Advanced Manufacturing Technology (AMT) Environments: A White Paper" International Journal of Industrial Ergonomics Vol. 24: pp. 173-184

Rothwell W.J., Kazanas, H.C. (2004). "Improving On-The-Job Training $-2^{\text {nd }}$ Edition" Pfeiffer \& Company, $1^{\text {st }}$ edition (July 1994)

Swamidass P. Schraedar M. (2003). "New Directions for on-the-job Training in Manufacturing" Development and Learning in Organizations Vol. 17: 10-12 


\begin{tabular}{|l|l|l|l|l|l|l|l|}
\hline & $\begin{array}{l}\text { Can } \\
\text { Assemble }\end{array}$ & $\begin{array}{l}\text { Can } \\
\text { Assemble } \\
\text { Hand } \\
\text { Actuator }\end{array}$ & $\begin{array}{l}\text { Can Deburr / } \\
\text { Sandblast }\end{array}$ & $\begin{array}{l}\text { Can } \\
\text { Inspect }\end{array}$ & $\begin{array}{l}\text { Can } \\
\text { Make } \\
\text { / Buy }\end{array}$ & $\begin{array}{l}\text { Can Pick } \\
\text { Material \& } \\
\text { Components }\end{array}$ & $\begin{array}{l}\text { Can } \\
\text { Welding }\end{array}$ \\
\hline Worker 1 & $\mathrm{X}$ & $\mathrm{X}$ & & & & & \\
\hline Worker 2 & $\mathrm{X}$ & $\mathrm{X}$ & & & & & $\mathrm{X}$ \\
\hline Worker 3 & & & & & & $\mathrm{X}$ & \\
\hline Worker 4 & $\mathrm{X}$ & $\mathrm{X}$ & & & & & $\mathrm{X}$ \\
\hline Worker 5 & & & & $\mathrm{X}$ & & & \\
\hline Worker 6 & & & & $\mathrm{X}$ & & & \\
\hline Worker 7 & & $\mathrm{X}$ & $\mathrm{X}$ & & & $\mathrm{X}$ & \\
\hline Worker 8 & & $\mathrm{X}$ & $\mathrm{X}$ & & & $\mathrm{X}$ & \\
\hline Worker 9 & & $\mathrm{X}$ & $\mathrm{X}$ & & & & \\
\hline Worker 10 & & $\mathrm{X}$ & $\mathrm{X}$ & & & & \\
\hline Worker 11 & & & & $\mathrm{X}$ & $\mathrm{X}$ & & \\
\hline
\end{tabular}

Table 1. Worker Skill Matrix for Schuff Data (Baseline)

\begin{tabular}{|c|c|c|c|c|}
\hline & $\sqrt{6}$ & $\begin{array}{l}\text { SCM } \\
\text { Reduction }\end{array}$ & $\begin{array}{l}\text { Machine RCM } \\
\text { Reduction }\end{array}$ & $\begin{array}{l}\text { Skill RCM } \\
\text { Reduction }\end{array}$ \\
\hline 1 & Magic Wand & $22.53 \%$ & & $99.49 \%$ \\
\hline 2 & Worker 11 - Welding & $14.53 \%$ & & $65.62 \%$ \\
\hline 3 & Worker 11 - Can Deburr/Sandblast & & & \\
\hline 4 & Worker 11 - Can Assemble & $14.87 \%$ & & $64.04 \%$ \\
\hline 5 & Worker 11 - Can Assemble Hand Actuator & & & \\
\hline 6 & Worker 11 - Can Pick Materials \& Components & $2.69 \%$ & & $13.15 \%$ \\
\hline 7 & Worker 1 - Can Deburr/Sandblast & & & \\
\hline 8 & Worker 1 - Can Inspection & & & \\
\hline 9 & Worker 1 - Can Make/Buy & & & \\
\hline 10 & Worker 1 - Can Pick Materials \& Components & & & \\
\hline 11 & Worker 1 - Can Welding & & & \\
\hline & Equal Mean \& Equal Variance & & & \\
\hline & Equal Mean \& Unequal Variance & & & \\
\hline & Unequal Mean \& Equal Variance & $\%$ & & \\
\hline & Unequal Mean \& Unequal Variance & $\%$ & & \\
\hline
\end{tabular}

Table 2. Reduction in Mean SCM/RCM Values WRT Baseline Experimental Model 
Figure 1. Pie Chart of SME Survey Results

Figure 2. Resource Constraint Metrics for Schuff Data (Baseline)

Figure 3. Worker Utilisation for Schuff Data (Baseline) 


\section{Simulation as a Useful Decision Making Tool for Worker Training in SMEs}

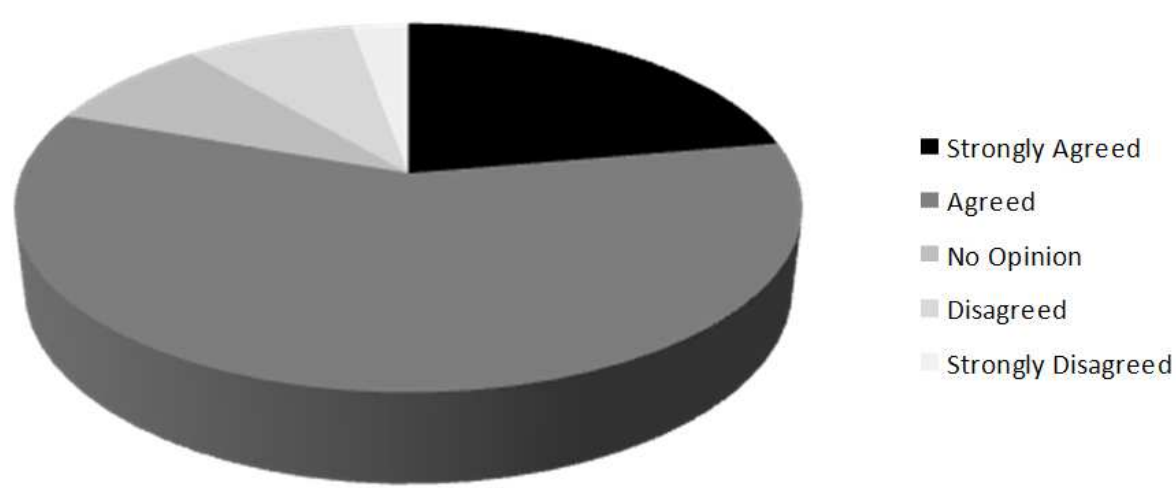

Pie Chart of SME Survey Results $251 \times 137 \mathrm{~mm}(96 \times 96 \mathrm{DPI})$ 


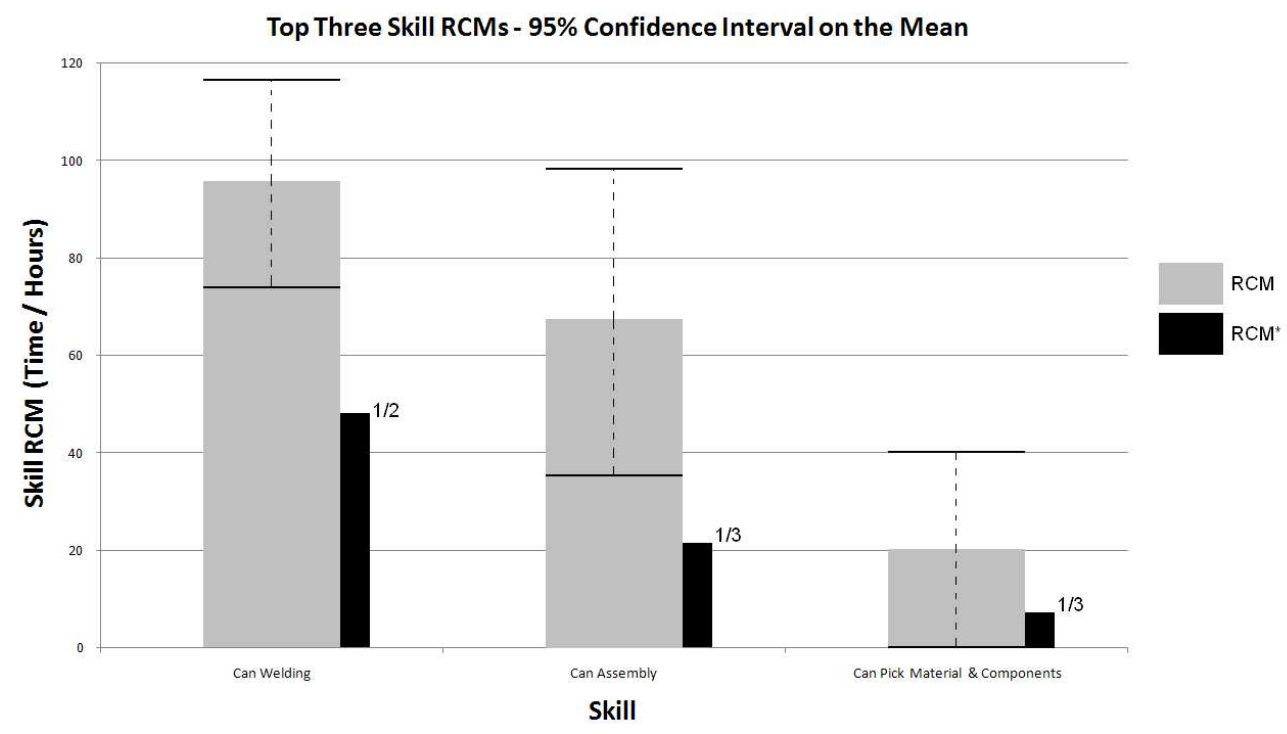

Resource Constraint Metrics for Schuff Data (Baseline) $336 \times 203 \mathrm{~mm}(96 \times 96$ DPI) 


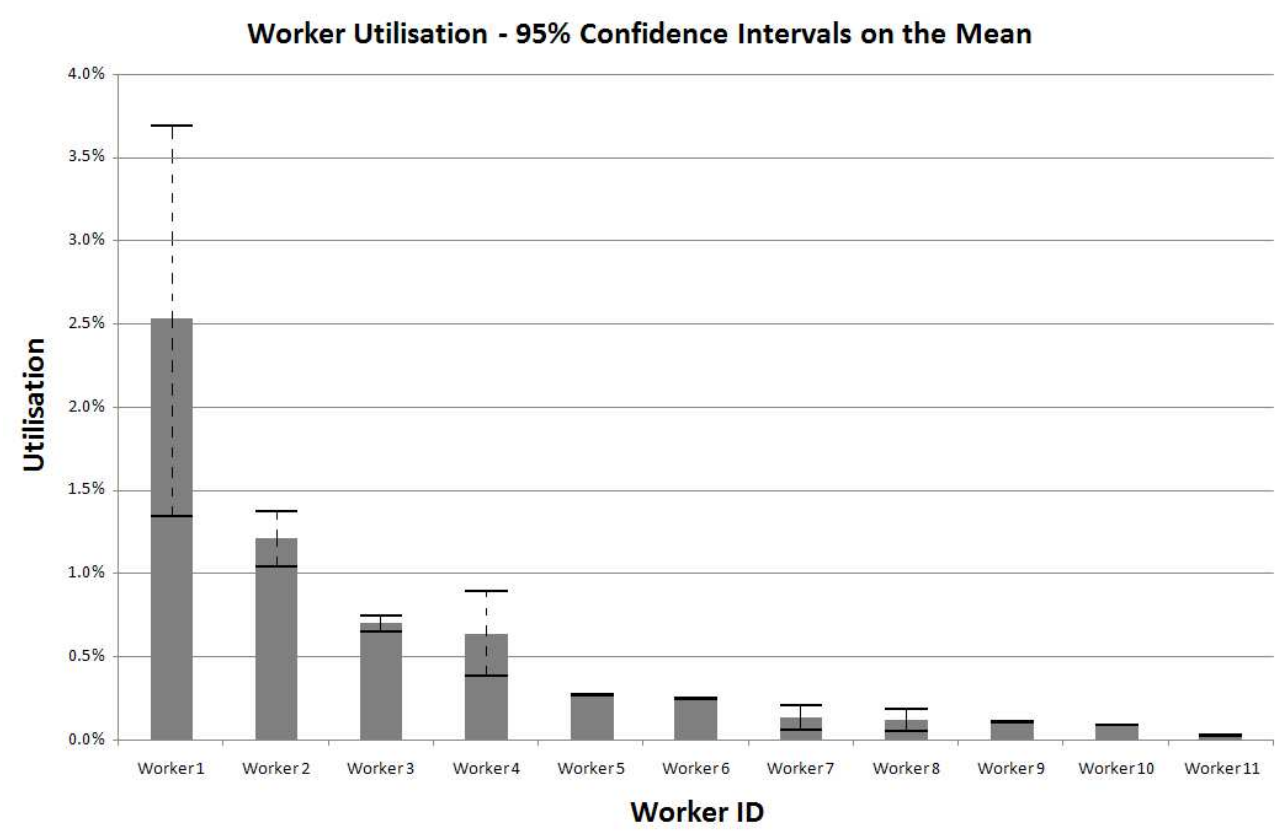

Worker Utilisation for Schuff Data (Baseline) $279 \times 185 \mathrm{~mm}$ (96 x 96 DPI) 